\title{
PENGARUH PENAGIHAN PAJAK TERHADAP PENCAIRAN TUNGGAKAN PAJAK PADA KANTOR PELAYANAN PAJAK (KPP) PRATAMA PADANG SATU
}

\author{
Twin Fitri Yanti, Dewi Zulvia \\ Sekolah Tinggi Ilmu Ekonomi "KBP" \\ dewi zulvia@gmail.com
}

\begin{abstract}
The purpose of this study is to examine the effect of tax collection on the disbursement of tax arrears on Tax Office (KPP) Pratama Padang. The object of this study is the taxpayer at the Tax Office (KPP) Pratama Padang. The amount of research data in this study is as many as 48 consisting of 4 tax periods namely the year 2013-2016. The data in this research is sourced from secondary data obtained from Tax Office (KPP) Pratama Padang. Data analysis using simple linear regression analysis. Based on the research result, tax collection variable has a positive and significant influence on the disbursement of tax arrears. This is evidenced from the result tcount> ttable and the level of significance is smaller than 0.05. The variable of disbursement of tax arrears can be explained by $97.9 \%$ by the tax collection variable and the rest is affected by other variables related to disbursement of tax arrears. For further research is expected to add research variables and the amount of data for more perfect research.
\end{abstract}

Keywords: Tax collection, disbursement of tax arrears

\begin{abstract}
ABSTRAK
Tujuan penelitian ini adalah untuk menguji pengaruh penagihan pajak terhadap pencairan tunggakan pajak pada Kantor Pelayanan Pajak (KPP) Pratama Padang. Objek dari penelitian ini adalah wajib pajak pada Kantor pelayanan Pajak (KPP) Pratama Padang. Jumlah data penelitian pada penelitian ini adalah sebanyak 48 yang terdiri dari 4 periode pajak yaitu tahun 2013-2016. Data pada penelitian ini adalah bersumber dari data sekunder yang didapat dari Kantor Pelayanan Pajak (KPP) Pratama Padang. Analisis data menggunakan anlalisis regresi linier sederhana. Berdasarkan hasil penelitian, variabel penagihan pajak memiliki pengaruh positif dan signifikan terhadap pencairan tunggakan pajak. Ini dibuktikan dari hasil $t_{\text {hitung }}>t_{\text {tabel }} d a n$ tingkat signifikansinya lebih kecil dari 0,05. Variabel pencairan tunggakan pajak dapat dijelaskan sebesar 97,9\% oleh variabel penagihan pajak dan sisanya dipengaruhi oleh variabel lain yang terkait dengan pencairan tunggakan pajak. Untuk penelitian selanjutnya diharapkan untuk menambah variabel penelitian dan jumlah data agar penelitian lebih sempurna.
\end{abstract}

\section{Kata kunci: Penagihan pajak, Pencairan tunggakan pajak PENDAHULUAN}

Pajak merupakan sumber utama penerimaan negara.Tanpa pajak, sebagian besar kegiatan negara sulit untuk dapat dilaksanakan. Penggunaan uang pajak yaitu dimulai dari belanja pegawai sampai dengan pembiayaan berbagai proyek 
pembangunan guna mencapai tujuan pembangunan Indonesia (Hadi, 2012). Salah satu sistem pemungutan pajak yang dianut oleh negara indonesia adalah self Assessment System. Menurut (Mardiasmo, 2009) Self Assessment System adalah suatu sistem pemungutan pajak yang memberi wewenang kepada Wajib Pajak untuk menentukan sendiri besarnya pajak yang terutang.

Penggelapan pajak adalah Tindakan yang melanggar Undang-undang Perpajakan, dengan menyampaikan jumlah SPT penghasilan yang lebih rendah daripada yang seharusnya di satu pihak dan melaporkan biaya yang lebih besar daripada yang sebenarnya dipihak ketiga. Tindak pengelapan pajak dapat dilihat dari beberapa kriteria yaitu wajib pajak tidak melaporkan harta yang sesungguhnya, membayar beban pajak terutang tidak sesuai dengan yang telah dibebankan, dan yang lebih parah alah tidak melpaorkan SPT.(Zulvia, 2018)

Peningkatan penerimaan pajak dapat tercapai apabila Wajib Pajak patuh dalam membayar pajak. Akan tetapi banyak Wajib Pajak yang dengan sengaja melakukan kecurangan-kecurangan dan melalaikan kewajibannya dalam melaksanakan pembayaran pajak yang telah ditetapkan sehingga menyebabkan timbulnya tunggakan pajak.Tunggakan pajak tersebut pada akhirnya membuat dirjen pajak harus melakukan penagihan pajak.

Pada tahun 2015, Tunggakan pajak di daerah Sumatera Barat dan Jambi mencapai Rp 7,77 miliar. Kantor Wilayah Direktorat Jenderal Pajak (DJP) Sumatra Barat dan Jambi mencekal lima wajib pajak (WP) dari 13 WP yang diusulkan pencegahan ke luar negeri dari daerah itu karena memiliki tunggakan pajak lebih dari Rp100 juta. Kepala Kanwil DJP Sumbar-Jambi, Teguh Budiharto menghimbau WP meningkatkan kesadaran dan kepatuhan untuk memenuhi kewajiban pembayaran pajak, agar terhindar dari penagihan pajak lebih lanjut.

Tunggakan pajak yang dilakukan Wajib Pajak kota Padang menyebabkan penerimaan pajak di Kota Padang menurun. Realisasi penerimaan pajak dari tahun 2015- 2016 tidak mencapai target yang ditetapkan. Hal tersebut dikarenakan adanya tunggakan pajak yang terjadi di KPP Pratama Padang oleh Wajib Pajak. Untuk menangani masalah tersebut, pemerintah khususnya Direktorat Jenderal Pajak (DJP) melakukan tindak penagihan pajak melalui surat teguran dan surat paksa.

Dari data yang didapat di KPP Pratama Padang, tunggakan pajak untuk tahun 2015-2016 adalah sebesar Rp 1.720.812.467, sementara pencairan pajak untuk tahun 2015-2016 adalah Rp 1.570.404.832. Jadi persentasi pencairan pajak pada tahun 2015-2016 adalah 95\%, tidak sesuai dengan target dari KPP Pratama Padang yaitu sebesar $98 \%$.

Jumlah minimal dari tunggakan pajak adalah Rp 50.000, sedangkan jumlah minimal dari pencairan pajak adalah $\mathrm{Rp}$ 0. Untuk jumlah maksimal dari tunggakan pajak adalah $\mathrm{Rp}$ 161.138.871, sedangkan jumlah maksimal dari pencairan pajak adalah $\mathrm{Rp}$ 9.134.921.

Untuk rata-rata tunggakan pajak tahun 2015-2106 adalah Rp 13.339.631, sedangkan rata-rata pencairan pajak yang diterima oleh KPP Pratama Padang adalah sebesar Rp 9.134.921.

Dari data yang didapat, penagihan pajak di KPP Pratama padang untuk tahun 2015-2016 belum optimal, karena pencairan tunggakan pajak tidak mencapai target. Untuk itu, pegawai KPP Pratama Padang sebaiknya menindak 
tegas oknum-oknum yang tidak membayar pajak sesuai peraturan yang dikeluarkan oleh Kementerian Keuangan dan Direktorat Jendral Pajak.

Penagihan pajak adalah serangkaian tindakan agar penanggung pajak melunasi utang pajak dan biaya penagihan pajak dengan melaksanakan penyitaan, melaksanakan penyanderaan, menjual barang yang telah disita. Penagihan dilaksanakan dengan ketentuan Undang-undang diharapkan dapat memberikan kepastian hukum dan keadilan masyarakat.Pajak yang dilunasi termasuk sanksi administrasi dalam masa tagihan pajak. Pencairan tunggakan pajak ini harus dibayar dengan surat setoran pajak, yang digunakan untuk membayar pelunasan utang pajak penanggung pajak untuk menambah penerimaan negara.

Penagihan pajak dapat dilakukan dengan surat teguran dan surat paksa. Penagihan pajak dengan surat teguran adalah tindakan awal dari proses penagihan pajak aktif. Surattegurandikirim ke Wajib Pajak bertujuan untuk menegur atau memperingatkan Wajib Pajak agar melunasi utang pajaknya (Ilyas \& Suhartono, 2013) dalam (Saputri, 2015). Surat teguran yang dikirim bertujuan untuk menegur atau memperingatkan Wajib Pajak agar membayar hutang pajaknya. Penagihan pajak dengan surat teguran diharapkan dapat memberikan pengaruh terhadap efektivitas pencairan tunggakan pajak (Saputri, 2015).

Menurut Undang-Undang Nomor 19 tahun 2000 tentang Penagihan Pajak dengan Surat Paksa menyatakan penagihan Pajak dengan Surat Paksa adalah perintah membayar utang pajak dan biaya penagihan pajak(Republik Indonesia, 2000). Surat Paksa disampaikan secara langsung oleh Jurusita Pajak kepada penunggak pajak dengan tujuan memaksa agar penunggak pajak membayar hutang pajaknya. Penagihan pajak dengan Surat Paksa diharapkan mampu membuat penunggak pajak membayar hutang pajaknya sehingga efektivitas pencairan tunggakan pajak dapat tercapai (Saputri, 2015).

Beberapa peneliiti sebelumnya telah melakukan peneliitian dengan judul serupa dan menemukan hasil yang berbeda.(Saputri, 2015) dalam penelitiannya menemukan hasil bahwa Penaigihan pajak dengan surat teguran dan surat paksa berpengaaruh signifikan terhadap efektivitas pencairan tunggakan pajak di KPP Pratama Bandung Cibeunying. Namun dalam penelitian yang dilakukan oleh (Pertiwi, 2014)didapatkan hasil bahwa Penagiihan pajak dengan surat teguran dan surat paksa tidak berpengaruh signifikanterhadap efektivitas pencairan tunggakan pajakpada KPP Pratama Bandung Karees.

\section{METODE PENELITIAN}

\section{Jenis Penelitian}

Berdasarkan jenis penelitiannya, peneliti mengunakan jenis penelitian deskriptif karena peneliti akan menggambarkan seberapa besar pengaruh penagihan pajak terhadap pencairan tunggakan pajak pada KPP Pratama Padang. Sementara pendekatan penelitian ini adalah penelitian kuantitatif karena peneliti akan melakukan pengujian teori dengan pengukuran variabel dengan angka-angka (Sekaran, 2009).

2. Objek Penelitian

Objek dari penelitian ini adalah Kantor Pelayaanan Pajak Pratama Padang untuk periode 2013 sampai 2016 yang beralamat di Jalan Bagindo Aziz Chan, Padang.

3. Jenis Penelitian 
Jenis data dalam penelitian ini adalah data sekunder. Data sekunder adalah data yang dikumpulkan oleh para peneliti, data yang diterbitkan dalam jurnal statistik dan lainnya, dan informasi yang tersedia dari sumber publikasi atau nonpublikasi dari dalam atau luar organisasi, semua yang dapat berguna bagi peneliti (Sekaran, 2009). Sedangkan sumber dari data peneliitian ini adalah data penagihan pajak dan data tunjakan pajak yang dikeluarka oleh KPP Pratama Padang satu.

4. Teknik Pengumpulan Data

Menurut (Sekaran, 2009) teknik dan pengumpulan data penelitian dilakukan dengan cara sebagai berikut :

1. Metode studi pustaka

Yaitu dengan melakukan telaah pustaka, eksplorasi dan mengkaji berbagai literatur pustaka seperti buku-buku, jurnal, masalah, literatur, dan sumbersumber lain yang berkaitan dengan peneilitian.

2. Dokumentasi

Yaitu mengumpulkan data dengan cara mencatat dokumen yang berhubungan dengan penelitian ini. Pencatatan data yang berhubungan dengan variabel yang diteliti.

5. Variabel Penelitian

a. Variabel Dependen

Pada penelitian ini yang menjadi variabel dependen adalah pencairan tunggakan pajak. Menurut surat edaran DJP Nomor SE-29/PJ/2012, pencairan tunggakan pajak atau piutang pajak adalah seluruh pembayaran dan pengurangan atas piutang yang terbit sebelum tahun berjalan.

b. Variabel Independen

Yang menjadi variabel independen di dalam penelitian ini adalah penagiihan pajak. Penagihan pajak yaitu serangkaian tindakan dan aparatur Direktorat Jendral Pajak karena wajib pajak tidak mematuhi ketentuan undang-undang khususnya mengenaii pembayaran pajak.

6. Teknis Analisis Data

a Uji Asumsi Klasik

1) Uji Normalitas

Uji normalitas bertujuan untuk melihat apakah data pada penelitian ini sudah terdistribusi secara normal apa belum. Apabila data telah terdistribusi secara normal, maka penelitian dapat dilanjutkan. Apabila data tidak terdistribusi secara normal, maka uji stastik menjadi tidak valid untuk jumlah sampel kecil (Ghozali, 2011). Pengujian normalitas residual dalam penelitian ini dilakukan dengan uji statistik non-parameterik Kolmogorov-Smirnov (K-S) yaitu dengan Level of Significant $(\alpha)$ yang digunakan adalah 0,05. Data dikatakan terdistribusi normal apabila nilai probabilitas signiifikannya diatas 0,05 (Ghozali, 2011).

2) Uji Homogenitas

Uji homogenitas adalah pengujian yang bertujuan untuk melihat apakah terjadi kesamaan atau ketidaksamaan variansi dua buah distribusi atau lebih. Untuk mengetahui apakah terjadi kesamaan atau ketidaks amaan variansii tersebut, pengujian yang digunakan di dalam penelitian ini adalah uji Barlet. Tujuannya yaitu untuk mengetahui 
apakah variabel $\mathrm{X}$ dan $\mathrm{Y}$ bersifat homogen atau tidak. Apabila nilai signifikansii nya lebih besar dari alpha 0,05 , maka variabel $\mathrm{X}$ dan $\mathrm{Y}$ bersifat homogen dan sebaliknya apabila nilai signifikansinya lebih kecil dari 0,05, maka variabel $\mathrm{X}$ dan $\mathrm{Y}$ bersifat tidak homogen.

b Uji Hipotesis

1) Analisis Regresi Sederhana

Menurut Sugiyono dalam (Kukuh Putranda Juniardi, Handayani, \& Devi Farah Azizah, 2014) analisis regresi berganda diigunakan untuk menjelaskan mengenai pengaruh antar variabel bebas secara bersamaan dengan salah satu variabel terikatnya.

2) Uji t (Parsial)

Uji statistik $\mathrm{t}$ digunakan untuk mengetahui seberapa jauh pengaruh satu variabel independen secara individual dalam menjelaskan variasi variabel dependen (Ghozali, 2011). Data penelitian yang telah diolah dianalisis dengan kriteria pengujian, yaitu:

a. Ho ditolak, Ha diterima yaitu bila nilai signifiikan kurang dari tingkat signifikan 0,05 berarti variabel independen secara individual berpengaruh terhadap variabel dependen atau,

b. Ho diterima, Ha ditolak yaitu bila nilai signifikan lebih dari tingkat signifikan 0,05 berarti variabel independen secara individual tidak berpengaruuh terhadap variabel dependen.

3) Uji Koefisien Determinasi $\left(R^{2}\right)$

Koefisien determinasi $\left(\mathrm{R}^{2}\right)$ bertujuan untuk mengetahui seberapa besar variabel dependen dapat dijelaskan oleh variabel independen. Nilai koefisien determinasi adalah antara nol dan satu. Nilai $\mathbf{R}^{2}$ yang kecil berarti kemampuan variabel-variabel independen dalam menjelaskan variabel dependen amat terbatas. Nilai yang mendekati satu berarti variabel-variabel independen memberikan hampir semua informasi yang dibutuhkan untuk memprediksi variasi variabel dependen (Ghozali, 2011).

\section{HASIL DAN PEMBAHASAN}

Pembentukan kantor pelayanan pajak pratama merupakan bagian dari prgram reformasi birokrasi perpajakan yang sifatnya komprehensif dan telah berjalan sejak tahun 2002 ditandai dengan dibentuknya terlebih dahulu kantor wilayah, KPP dibentuk untuk meningkatkan dalam memberikan playanan yang lebih baik dan personal kepada wajib pajak dlam pelaksanaan good governance.

Kantor Pelayanan Pajak (KPP) Pratama Padang berada di bawah kantor wilayah Direktorat Jendral Pajak Sumatera Barat dan Jambi yang berlokasi di Jalan Khatib Sulaiman No. 53 Padang. KPP Pratama dibentuk berdasarkan Surat Keputusan Menteri Keuangan Republik Indonesia No. 276/KMK/01/1989, kantor pelayanan pajak adalah instansi vertikal Direktorat Jenderal Pajak yang berada dalam tanggungan Kanwil setempat.

Kantor Pelayana Pajak (KPP) Pratama Padang dipecah menjadi dua bagian pada tanggal 05 Oktober 2015 yang mana wilayah kerja KPP Pratama Padang Dua meliputi ; Kab. Mentawai, Kab, Pesisir Selatan, Kec. Bungus Teluk 
Kabung, Kec. Lubuk Kilangan, Kec. Lubuk Begalung, Kec. Padang Selatan, Kec. Padang Timur, Kec. Pauh.

\section{Uji Asumsi Klasik}

\section{a Uji Normalitas}

Dari hasil uji normailitas, nilai dari kolmogorov-smornov (k-s) nya adalah 0,429 . Nilai tersebut lebih besar dari 0,05, itu berarti bahwa data terdistribusi secara normal.

b Uji Homogenitas

Dari hasil uji homogenitas, nilai signifikansi dari uji homogenitas di atas adalah 0,898 lebih besar dari alpha 0,05. Dapat disimpulkn bahwa variabel $\mathrm{X}$ dan Y bersifat homogen.

\section{Analisis Regresi Linier Sederhana}

Persamaan yang didapat pada uji analisis regresi sederhana pada penelitian ini adalah sebagai berikut:

\section{Uji t (Parsial)}

$$
\mathrm{Y}=1,112-0,965 \mathrm{X} 1+\mathrm{e}
$$

Variabel penagihan pajak mempunyai nilai t test (thitung) sebesar 47,006 dengan tingkat signifikansi sebesar 0,000 (di bawah 0,05). Memperhatikn hasil uji t test ini, maka Ha yang menyatakn bahwa penagihan pajak memiliki pengaruh positif dan sgnifikan terhadap pencairan tunggakn pajak diterima.

\section{Uji Koefisien Determinasi $\left(\mathbf{R}^{2}\right)$}

Pada tabel 4.6 , menunjukkan bahwa nilai koeefisien Adjusted $R$ Square adalah sbesar 0,979, hal ini berarti 97,9\% variabel pencairn tunggakn pajak dapat dijelaskan oleh variabel penagihan pajak. Sedangkan sisanya $(100 \%-97,9 \%=$ 0,21\%), dpengaruhi oleh variabel-variabel lain yang terkait dengan pencairan tunggakn pajak yang tidak diteliti dalam pnelitian ini. Angka koefisien korelasi (R) sebesar 0,990 menunjukn bahwa hubungan antara variabel independen dengan variabel dependn adalah kuat karena memiliki nilai koefisien korelasi di atas 0,05.

\section{Pembahasan}

\section{Pengaruh Penagihan Pajak Terhadap Pencairan Tunggakan Pajak}

Berdasarkan perhitungan didapat bahwa pada uji $t$, variabel penagihan pajak mempunyai nilai t hitung sebesar 47,006 dengan signifikansi sebesar 0,000 (kecil dari 0,05). Dengan demikian Ha yang menyatakan bahwa penagihan pajak memiliki pengaruh positif dan signifikan terhadap pencairan tunggakan pajak diterima. Hasil penelitian ini menunjukan bahwa semakin baik penagihan yang dilakukan oleh jurusita pajak maka semakin tinggi pencairan tunggakan wajib pajak. Hal ini disebabkan karena wajib pajak yang memiliki hutang pajak akan membayar semua hutang pajaknya setelah dilakukan penagihan pajak.

Penelitian ini sejalan dengan penelitian yang dilakukan oleh(Rudi Hidayat, 2013),(Saputri, 2015), Desi Siti Patimah, 2015)dengan hasil penelitiannya menyatakan bahwa penagihan pajak memiliki pengaruh positif dan signifikan terhadap pencairan tunggakan pajak. 
Penelitian ini tidak relevan dengan penelitian yang dilakukan oleh Pertiwi (2014) dengan hasil penelitiannya menyatakan bawah penagihan pajak tidak memiliki pengaruh signifikan terhadap pencairan tunggakan pajak.

\section{PENUTUP}

\section{Kesimpulan}

1. Berdasarkan hasil analisis dan pembahasan pada BAB IV dapat diketahui bahwa penagihan pajak memiliki pengaruh positif dan signifikan terhadp pencairan tunggakn pajak pada KPP Pratama Padang. Hasil ini diketahui nilai t hitung nya sebesar 47,006 dan tingkat sgnifikansinya adalah 0,000 lebih kecil dari 0,05 .

2. Hasil koefosien determinasi $\left(\mathrm{R}^{2}\right)$ menunjukkn bahwa nilai koefisien Adjusted $R$ Square adalah sebesar 0,979, hal ini berarti 97,9\% variabel pencairan tunggakn pajak dapat dijelaskn oleh variabel penagihan pajak. Sedangkan sisanya $(100 \%-97,9 \%=0,21 \%)$, dpengaruhi oleh variabelvariabel lain yang terkait dengan pencairan tunggakn pajak yang tidak diteliti dalam penelitian ini. Angka koefisien korelasi (R) sebesar 0,990 menunjukn bahwa hubungaan antara variabel independn dengan variabel dependen adalah kuat karena memilki nilai koefisien korelasi di atas 0,05.

\section{Saran}

Berdasarkn hasil penelitian, maka pennulis mengajukan saran - saran sebagai brikut:

1. Untuk meningkatkan Pencairan Tunggakn Pajak tidak hanya mengandalkn penagihan pajak saja melainkan dilakukannya tindak penegasan yang lebih dalam melakukn peneguran atau memberikan pringatkan kepada wajib pajak yang memiliki tunggakn pajak agar segera melunasi hutang pajaknya. Dan melakukn peyuluhan kepada wajib pajak agar melunasi hutang pajaknya sehingga pencairan tunggakn pajak tidak terhambat dimana jika pencairan tunggakan pajak terhambat maka akan berdampak pada penerimaan Negara.

2. Untuk meningkatkan Pencairan Tunggakn Pajak harus menegakn hukum yang lebih tegas kepada wajib pajak yang memiiliki tunggakan pajak, agar wajib pajak lebih taat dalam menjalankn kewajibannya untuk membayarkn hutang pajaknya shingga tidak mengakibatkn pencaiiran tunggakn pajak terhambat.

\section{Daftar Pustaka}

Ghozali, I. (2011). Aplikasi Analisis Multivariate Dengan Program SPSS. Semarang: Badan Penerbit Universitas Diponegor.

Hadi, W. Mengamankan Penerimaan Pajak Di tengah Lesunya Ekonomi Dunia (2012). 
Ilyas, W. B., \& Suhartono, R. (2013). Hukum Pajak Material 1: Seri Pajak Penghasilan. Salemba Humanika. Jakarta: Salemba Humanika.

Indonesia, R. (2000). Undang-Undang Nomor 19 tahun 2000 tentang Penagihan Pajak dengan Surat Paksa. Jakarta: Sekretariat Negara.

Kukuh Putranda Juniardi, Handayani, S. R., \& Devi Farah Azizah. (2014). Pengaruh Surat Ketetapan Pajak dan Tindakan Penagihan Aktif Terhadap Pencairan Tunggakan Pajak Penghasilan Badan, 1-8.

Mardiasmo. (2009). Perpajakan. Jakarta: ANDI.

Pertiwi, D. P. (2014). Pengaruh Penagihan Pajak Dengan Surat Teguran Dan Surat PasaTerhadap Efektivitas Pencairan Tunggakan Pajak, 1-17.

Rudi Hidayat, C. C. (2013). Pengaruh Kualitas Penetapan Pajak Dan Tindakan Penagihan Aktif Terhadap Pencairan Tunggakan Pajak, 1-20.

Saputri, H. A. (2015). Pengaruh Penagihan Pajak Dengan Surat Teguran dan Surat Paksa Terhadap Efektivitas Pencairan Tunggakan Pajak ( Studi Kasus KPP Pratama Bandung Cibeunying Periode 2010-2014 ). E Proceeding of Management, 2(2), 1814-1820.

Sekaran, U. (2009). Research Methods For Business (Metodologi Penelitian Bisnis). Jakarta: Salemba Empat.

Zulvia, silvia reswina dan dewi. (2018). ANALISIS PENGARUH SISTEM

PERPAJAKAN DAN PEMERIKSAAN PAJAK TERHADAP

PENGGELAPAN PAJAK PADA PERUSAHAAN HOME INDUSTRY DI KOTA PADANG. - . 